\title{
Application in the dental office of a practical method of clinical-behavioural treatment for smoking cessation: a case report
}

\author{
Leonardo Essado Rios ${ }^{a}$, Maria do Carmo Matias Freire ${ }^{b}$, Nádia Lago Costa ${ }^{c}$
}

\begin{abstract}
INTRODUCTION: Smoking causes harmful effects to the oral cavity, therefore dentists play an important role in helping their patients to quit.

OBJECTIVE: In this article, we aimed to report the application of a practical method of clinicalbehavioural treatment for smoking cessation which was performed by a Dental Surgeon in a male patient who wanted to stop smoking.

CASE DESCRIPTION: Behavioural support was based on the Standard Treatment Program (STP) recommended by an English institution specialized in preparing health professionals to promote smoking cessation. Drug support involved Nicotine Replacement Therapy (NRT) by the combination of transdermal patches and chewing gums in different stages and dosages. The Fagerström Test was used to assess the patient's level of nicotine dependence. Abstinence was monitored by assessing the patient's level of expired carbon monoxide using a monoximeter. Success in promoting patient's abstinence was observed during 40 days of treatment and one year of follow-up.

CONCLUSION: The STP behavioural support methodology combined with NRT proved to be quite feasible and promising to be used by dentists in order to treat smoking in the dental office.
\end{abstract}

Keywords: dentistry; dental care; smoking cessation; nicotine; behaviour.

\section{Aplicação no consultório odontológico de um método prático de tratamento clínico-comportamental para cessação do tabagismo: relato de caso}

\section{RESUMO}

INTRODUÇÃO: O tabagismo causa efeitos nocivos à cavidade oral, portanto os dentistas possuem importante papel para auxiliar seus pacientes a abandonar o hábito.

OBJETIVO: Neste artigo, busca-se relatar a aplicação de um método prático de tratamento clínico-comportamental para cessação do tabagismo, o qual foi realizado por um Cirurgião-Dentista em um paciente do sexo masculino que desejava parar de fumar.

DESCRIÇÃO DO CASO: O suporte comportamental foi baseado no Programa de Tratamento Padrão (PTP) preconizado por uma instituição inglesa especializada em preparar profissionais de saúde para promoverem a cessação do tabagismo. O suporte medicamentoso envolveu a Terapia de Reposição de Nicotina (TRN) pela combinação de adesivos transdérmicos e gomas de mascar, em diferentes etapas e dosagens. O Teste de Fagerström foi utilizado para avaliar o nível de dependência de nicotina do paciente. A abstinência foi monitorada por meio de um monoxímetro para avaliação do nível de monóxido de carbono expirado pelo paciente. Verificou-se êxito em promover a abstinência do paciente durante 40 dias de tratamento e um ano de acompanhamento. CONCLUSÃO: A metodologia para suporte comportamental do PTP, em combinação com a TRN se mostrou bastante viável e promissora para ser utilizada por cirurgiões-dentistas a fim de tratar o tabagismo no consultório odontológico.

Palavras-chave: odontologia; assistência odontológica; cessação do hábito de fumar; nicotina; comportamento. a Oral Health Coordination, Inhumas Campus, Federal Institute of Goiás, Brazil

${ }^{\mathrm{b}}$ Department of Oral Health, School of Dentistry, Federal University of Goiás, Brazil

c Department of Stomatology, School of Dentistry, Federal University of Goiás, Brazil

\section{Correspondence: Leonardo Essado Rios leonardo.rios@ifg.edu.br \\ Received: January 13, 2017 Accepted: January 16, 2018}

Conflict of Interests: The authors state that there re no financial and personal conflicts of interest that could have inappropriately influenced their work.

Copyright: ( 2017 Rios et al licensee EDIPUCRS.

This work is licensed under a Creative Commons Attribution 4.0 International License. 


\section{INTRODUCTION}

The harmful effects of smoking in the oral cavity are vast and include discolorations of teeth and restorations, reduced taste, dental caries, implant failures, periodontal diseases, potentially malignant lesions and cancer [1-4]. More than a half of the cases of oral cancer diagnosed annually in the world are lethal and, given the knowledge about the risk factors for the disease, the eradication of smoking as a form of prevention is fundamental [5].

The effectiveness of some drugs to treat smoking dependence has already been demonstrated. Seven topof-the-line drugs have been proven to increase long-term smoking cessation rates: Bupropion, Varenicline and Nicotine Replacement Therapy (NRT) products - chewing gums, inhalers, nasal spray, lozenges and transdermal patches [6].

In addition, there is evidence that offering some kind of behavioural support to the patient is also effective, e.g., individual counselling done in person or by telephone, and the combination of this type of support and medication increases success rates in the interventions aimed at smoking cessation [7].

Dentists are ideally placed to promote smoking cessation, especially because they have a good credibility to guide patients about the harm associated with smoking, but also because they have more frequent access to patients and can easily identify their status in relation to smoking $[3,4,8,9]$. In general, these professionals recognize that they play an important role in smoking cessation and are aware of the oral health problems caused by the addiction. In spite of that, the approach of smokers in dental offices does not happen effectively, since most dentists still have limited knowledge and skills to promote smoking cessation [10-13].

Thus, initiatives to promote smoking cessation in the dental setting - using a systematic and evidence-based manner - are relevant to contribute to the practice of Dental Surgeons (DS) when helping their patients to stop smoking, consequently preventing diseases and benefiting their oral and general health. However, there are no studies in the literature that have detailed procedures for the treatment of smoking in the dental clinic. Thus, in the present study, we aimed to report the application in a dental office of a practical method of clinical-behavioural treatment for smoking cessation.

\section{CASE DESCRIPTION}

Location: The present work was carried out in a Brazilian mid-west region reference centre for the prevention, diagnosis and treatment of affections of the bucomaxillofacial complex - during the months of September and October, 2016.

Patient approach: we used the Very Brief Advice (VBA) method based around the 3A'S - Ask, Advise and Act - to approach the patient. VBA is a simple method for counselling smokers, which was designed to be used in less than 30 seconds during unspecific consultations with health professionals. Such approach (available in: www.ncsct.co.uk) is recommended by the English institution denominated as National Centre for Smoking Cessation and Training (NCSCT) and involves: (i) Ask the patients whether they are smokers or not, (ii) Advise smokers that the best way to stop smoking is a combination of behavioural support and pharmacological treatment and (iii) Act by suggesting the scheduling of a consultation or by referring the patient to a specialized service. In our case, this VBA method was applied during a routine dental visit. After patient agreement, a specific appointment was scheduled in order to start the cessation treatment.

Patient information: The selected patient was male, 47 years old and had been smoking for 30 years, that is, since his adolescence. At the time, he worked as a bus driver on an interstate highway. He reported previous attempts to stop smoking on his own, but to no avail.

Description of treatment: The patient received a treatment for smoking cessation involving behavioural support and NRT - transdermal patches and nicotine chewing gum. The consultations were held weekly and treatment lasted eight weeks.

Documentation of the case: All the consultations were filmed and photographs were also obtained. After explaining about the finality of the images - for exclusively didacticscientific purposes, preserving his identity - the free consent of the patient was obtained.

Nicotine Replacement Therapy: transdermal patches (Nicotinell ${ }^{\circledR}$, Novartis, Avlona, Greece) and chewing gums (Nicorette $^{\circledR}$, Johnson \& Johnson, Helsingborg, Sweden) were provided over eight weeks post-cessation. The following therapeutic regimen was adopted (based on manufacturers' recommendations): in the first four weeks post-cessation, $21 \mathrm{mg}$ patches and $4 \mathrm{mg}$ chewing gums were used; in the $5^{\text {th }}$ and $6^{\text {th }}$ weeks, patches of $14 \mathrm{mg}$ and gums of $2 \mathrm{mg}$; and in the last two weeks, patches of $7 \mathrm{mg}$ and gums of $2 \mathrm{mg}$.

Behavioural support: We followed the NCSCT Standard Treatment Program (STP) [14], which is available on its website, where one can find online smoking cessation training for health professionals, video-lessons and other didactic, clinical, and scientific resources, all based on the best evidence available. The STP is developed in three stages: (i) a pre-quit assessment consultation, (ii) a quit date consultation, and (iii) four post-quit consultations. For all stages, there are scripts to guide the health professional during the consultations, which are presented in Table 1.

To deliver the STP program, the following communication skills are required: (i) to increase the motivation and boost self-efficacy of patients, (ii) to build a harmonious relationship with them, (iii) to use attentive and reflective listening, (iv) to provide them confidence and reassurance and (v) to promote their identity as former smokers [14].

In addition, the NCSCT recommend that professionals delivering stop smoking support should know about: (i) the epidemiology of smoking, (ii) its harmful effects and the benefits of quitting, (iii) the difficulties to quit, (iv) the principles of smoking cessation treatments and (v) smoking in the wider context of public health [15]. 
Table 1. Scripts for Standard Treatment Program consultations - National Centre for Smoking Cessation and Training, United Kingdom, 2016.

\begin{tabular}{|c|c|c|}
\hline Pre-quit assessment & Quit date & Post-quit consultations \\
\hline 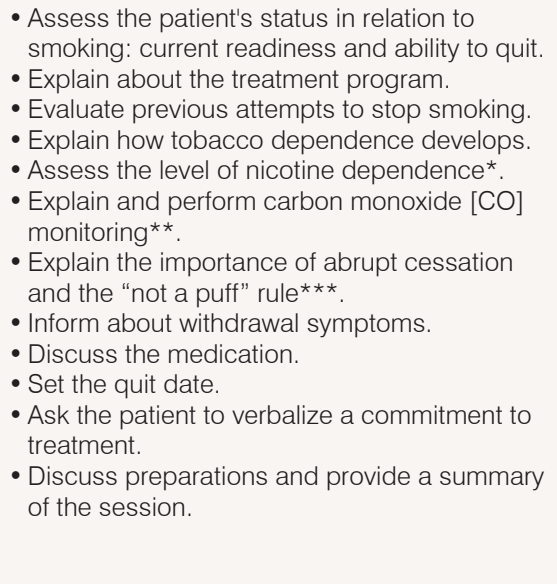 & $\begin{array}{l}\text { - Confirm the patient's readiness and ability to } \\
\text { stop smoking. } \\
\text { - Check for sufficient supply and discuss } \\
\text { expectations regarding medication. } \\
\text { - Reinforce the symptoms of smoking cessation } \\
\text { and cravings and how to deal with it. } \\
\text { - Advise on necessary changes in routine. } \\
\text { - Discuss how to deal with the patient's contact } \\
\text { with smokers and how to get social support } \\
\text { while trying to quit smoking. } \\
\text { - Discuss any potential risk situation in the } \\
\text { coming week. } \\
\text { - Measure expired Co. } \\
\text { - Confirm the importance of abrupt cessation } \\
\text { and the "not a puff" rule. } \\
\text { - Ask the patient to verbalize a commitment to } \\
\text { treatment. } \\
\text { - Discuss engagements and provide a } \\
\text { summary. }\end{array}$ & $\begin{array}{l}\text { - Check the progress of the patient and } \\
\text { measure expired CO. } \\
\text { - Check for sufficient supply and enquire about } \\
\text { medication use. } \\
\text { - Reaffirm the importance of the "not a puff" rule } \\
\text { and prompt a commitment. } \\
\text { - Discuss withdrawal symptoms or cravings and } \\
\text { how the patient handled / will handle it. } \\
\text { - Discuss about difficult situations and how the } \\
\text { patient dealt / will deal with them. } \\
\text { - Discuss any potential risk situations in the } \\
\text { upcoming week or in the future, } \\
\text { post-treatment. } \\
\text { - Last consultation: advise on additional post- } \\
\text { treatment support if necessary. } \\
\text { - Last consultation: advise on what to do in } \\
\text { case of post-treatment lapse. } \\
\text { - Discuss engagements and provide a } \\
\text { summary. }\end{array}$ \\
\hline
\end{tabular}

* Using the Fagerström Test or Smoking Intensity Index.

** Using a monoximeter.

*** The main rule of the treatment, in which the patient agrees not to smoke even a puff after quit date, emphasizing that relapses begin with a single puff

Pre-quit consultation: The NCSCT script for this consultation was fully implemented and adequately addressed the smoker patient's approach in the dental office. The time spent in this consultation was approximately 30 minutes.

The main motivations for quitting smoking reported by the patient were: (i) to preserve health, (ii) to respond to the call of his children for him to quit, (iii) to have better job opportunities, (iv) to improve sleep, taste, smell and the disposition for physical activities and (v) stop spending money with cigarettes. He said he was ready to completely abandon his 30-year addiction and reported that situations of emotional stress and anxiety tended to increase his desire to smoke.

To evaluate his nicotine dependence level, the Fagerström Test was used, which resulted in a four-point score, indicating a moderate level of dependence. The score revealed that he (i) used to smoke the first cigarette of the day between 5 and 30 minutes after waking, (ii) considered that cigarette the hardest to quit, and (iii) used to smoke between 11 and 20 cigarettes a day.

When questioned about his expectancy on the main difficulties he was about to face by quitting smoking, the patient reported that he used to work at nights and occasionally feel sleepy, so he would stop the bus by the roadside and flee for a quick smoke as a strategy to overcome sleepiness.

However, he admitted that it was not the cigarette itself that kept him from drowsiness, but the fact that he was moving from the bus cabin. So, he did not think it would be such a difficult problem to get around.

The benefits to his health, especially his oral health, were also discussed. By the end of the appointment, a date was set for him to stop smoking a week later.

Quit date consultation: The NCSCT script for this consultation was fully implemented and adequately suited the smoker patient's approach in the dental office. Time spent in this consultation was approximately 35 minutes.
When asked if he was prepared to stop smoking for good from that moment on, the patient answered yes. He was asked to confirm in a loud voice the commitment not to smoke even a puff from that moment on.

He reported to have smoked the last cigarette half an hour before the appointment and agreed to get rid of cigarette lighters, ashtrays and cigarettes from that moment on.

Measurement of expired $\mathrm{CO}$ level using the monoximeter (Micro $\mathrm{CO}^{\circledR}$, Carefusion, Basingstoke, United Kingdom) with a disposable mouthpiece in order to avoid crosscontamination (Figure 1) resulted in a value of $16 \mathrm{ppm}$. Such value is compatible with a smoker, which was already expected since the patient had not yet started drug treatment and abstinence.

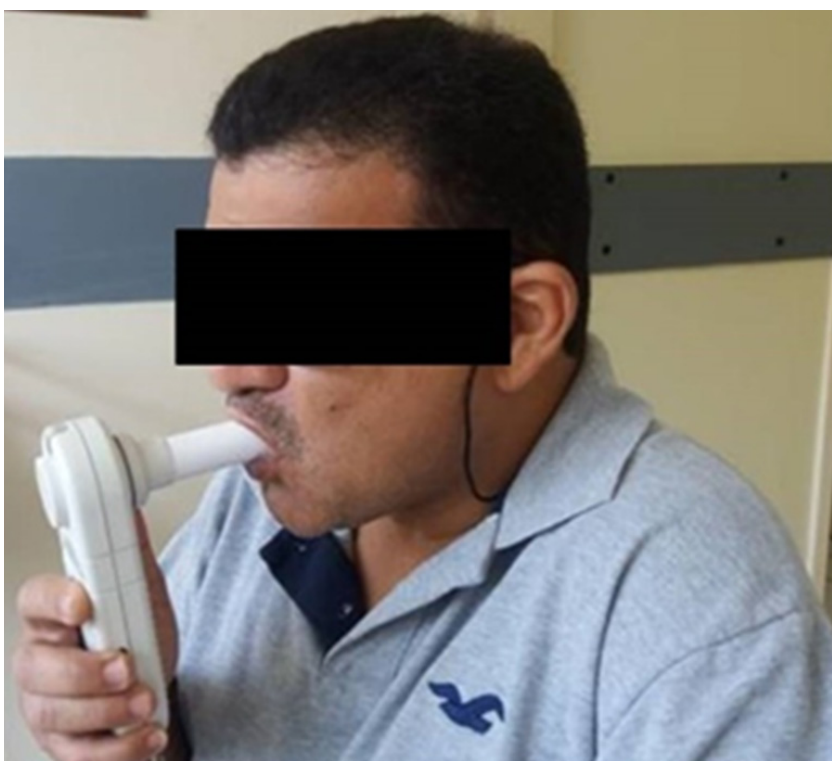

Figure 1. Measurement of expired CO using a monoximeter. 
The patient was carefully advised on the use of the patches (in order to vary the application site to avoid irritations and to use them for 24 hours, changing daily) and chewing gum (chew slowly for about half an hour, trying to keep the gum static nearby his oral mucosae in order to allow the absorption of nicotine). In Figure 2, the nicotine patch positioned on the patient's skin is visualized.

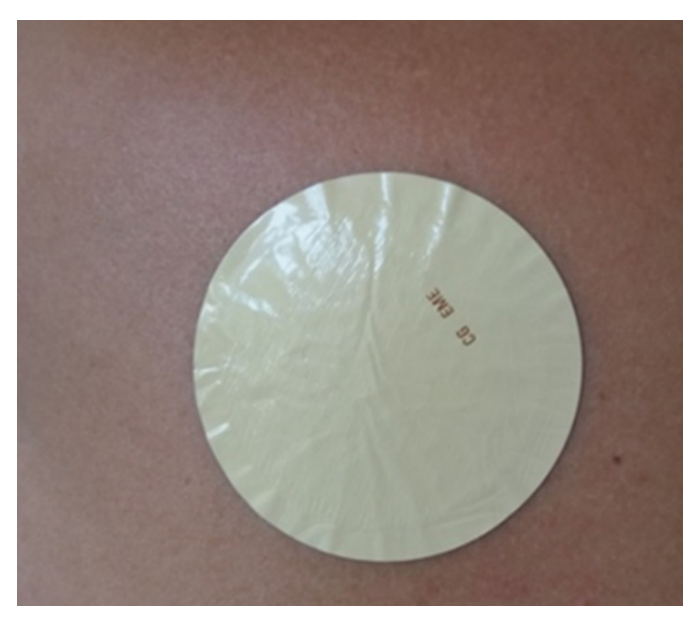

Figure 2. Nicotine transdermal patch positioned on the patient's skin, below left shoulder.

Post-quit consultations: The NCSCT script was fully implemented and the average time spent in these consultations was approximately 20 minutes. The DS would start post-quit consultations by praising the patient for his compliance with the "not a puff" rule.

He had no difficulty with medication and chewing gum was very supportive if he felt urges to smoke. At each visit, he would receive the nicotine patches and gums' supply for the following week.

The outcome of expired $\mathrm{CO}$ measurement confirmed his complete abstinence in the post-cessation period, ranging from zero to six parts per million, wich are levels compatible with non-smokers. He was always very proud and enthusiastic with the results of the CO test, since he started to realize the beneficial effects of the cessation.

In the first week of abstinence, he reported feeling cravings for smoking, but when this occurred he chewed a gum and after a few minutes the urge to smoke totally disappeared. Another withdrawal symptom reported throughout the postcessation period was an increase in appetite, which raised concern about weight gain, but he would overcome by incorporating physical activities to routine.

It should be noted that the mobile app Whatsapp (Facebook Inc.) was used to monitor the patient at a distance. Thus, the DS kept an open channel for the purpose of contributing to his motivation.

Also, the patient would occasionally report a moderate consumption of alcoholic beverage after quit date, without having, however, an increase in the desire to smoke. Likewise, he reported that although he was fearful of drinking coffee because of the risk of cravings, he was able to consume the drink without smoking then replacing the cigarette by a nicotine gum.

By the end of each consultation we would request him to present any doubts and to reaffirm his commitment to the "no a puff" rule, in addition we would advise him on the risk of putting all the treatment to lose. At all times, aware of the risk and reaffirmed, at each visit, the commitment to complete abstinence.

The last visit occurred after 40 days of cessation, when he was discharged from the behavioural treatment, but still received the last supply of NRT for the subsequent two weeks. In this consultation, the patient was accompanied by his non-smoker wife who was glad for his achievements and then we encouraged her to keep supporting her husband in the future.

The patient was highly praised - by the DS and auxiliary staff - and his identity as an ex-smoker was reinforced. He was asked to, in a loud voice, promise himself and the professional that he would remain firm in his decision, what he did promptly. Still, he received a thank-you card where we listed the motives to stop smoking which he had reported in the pre-quit assessment consultation. As coping strategy, he was oriented to keep the card in his wallet and picking it up to read in case he felt any negative thinking for smoking in the future, remembering everything he went through to get rid of the addiction.

By the end of the treatment, the patient estimated that he had saved a considerable amount of money which would have been spent on cigarettes, what was helpful to the family budget.

He also reported that he felt an improvement in his breath and tasting, thus indicating an improvement in his oral health. Finally, he was asked to evaluate the treatment received, so he said he was very satisfied and would indicate the treatment for other smokers.

We followed him up to one year after quit date using Whatsapp. During this period, he kept reporting us the maintenance of a complete abstinence and no relapse.

\section{DISCUSSION}

In this article, we describe how a treatment for smoking cessation was successfully carried out in a dental office using the association between behavioural support and NRT. It is known that offering medication support is much more effective than just behavioural support and vice versa $[16,17]$. The chances of a person succeed in an attempt to stop smoking more than double when there is specialized assistance and professional advice. Thus, offering help through referral to a specialized service or even offering the treatment itself makes a significant difference [16].

In addition, it is recommended that patients be encouraged to abrupt rather than gradual cessation, as evidence suggests that quitting abruptly is more conducive to long-term abstinence [18]. Still, offering care to all smokers is more effective than offering only to smokers who express 
an interest in quitting. In other words, evaluating in advance whether there is an intention to stop smoking excludes many patients who might have accepted the offer of care if it had been done directly. Similarly, offering help rather than simply telling the patient to stop smoking is much more effective [16].

Nicotine - a highly addictive drug - takes less than eight seconds to reach the smoker's brain, who usually smokes in order to keep its levels in the body and stay away from withdrawal symptoms [19]. Such symptoms may include: cravings, irritability, anxiety, difficulty to concentrate, agitation, sleeping complications, decreased heart rate, increased appetite and weight gain. However, they can be relieved by NRT $[20,21]$.

In this study, the patient received the treatment and did not show strong withdrawal symptoms, but reported that his appetite had increased, which was overcome through physical activity, thus providing him one more health gain. In addition, he had cravings for smoking at some point and the use of nicotine gum was important to help resisting the temptation to smoke.

The monoximeter device was easily used and proved to be quite suitable for dental clinical use in order to confirm abstinence, which was perceived as an extra motivation for the patient during treatment. Another very common way of monitoring cigarette exposure is through salivary cotinine, the nicotine metabolite, but it requires laboratory analysis and higher costs [18]. Furthermore, it would be inappropriate for treatments based on nicotine replacement, since the therapeutic nicotine would eventually generate false-positive results.

In the present case, the patient noticed, after 40 days of abstinence, improvements in his oral health, domestic budget and also incorporated physical activities to his routine, as a way to overcome the increase of appetite. There have probably been many other gains, as there is strong evidence that cessation of smoking brings significant improvements to oral and general health.

Smoking cessation reduces the risk of cancer by about $60 \%$ after four years of cessation, while the risk equals that of those who never smoked after twenty years of quitting [22]. The following reasons for cessation of smoking should be mentioned as well: reduces the risk of halitosis, improves the appearance of teeth, increases disposition and energy, breaks cigarette addiction, reduces the risk of cancer and cardiovascular disease, improves periodontal health, increases the chance of maintaining teeth for life and success in surgical treatments [23].

Hence, it is clear to see the importance of the effective involvement of Dentistry with activities aimed at smoking cessation. Some facts should be pointed out to reinforce the importance of incorporating smoking cessation assistance into dental practice: access to patients [frequent visits, possibility of follow-up], the infrastructure of the dental office [auxiliaries can be trained to screen patients], knowledge of harmful effects on oral health, ease of training, possibility of reimbursement or financial incentive [24]. In this way, one could presume that such treatment has the potential to be charged in dental practice - what may be an extra motivation for the DS to incorporate smoking cessation to clinical routine.

But a preparation of the professionals is necessary so they can safely deliver smoking cessation treatments in their offices and be compensated for it. The cost-benefit to patients lies in the fact that instead of spending money on cigarettes they will be investing in their health and quality of life.

In conclusion, a very promising possibility of clinical conduct to promote smoking cessation in the dental office was presented in this article. Long-term success was observed in the treatment of a patient with moderate nicotine dependence. It should be mentioned that there is previous evidence that smoking cessation treatment using NRT in Dentistry is effective in terms of long-term [one year] abstinence rates [25]. Furthermore, NRT is effective for smokers who have higher levels of nicotine dependence [20].

\section{CONCLUSION}

The treatment described in this article was performed by a DS who aimed to help his patient to stop smoking by using an association of NRT and behavioural support. Success in promoting patient abstinence was observed during 40 days of treatment and one year of follow-up. The 3A's NCSCT Very Brief Advice method - Ask, Advise, Act - proved to be suitable for the approach of the smoker patient during a routine dental visit. In addition, the NCSCT Standard Treatment Program for behavioural support, associated with NRT, was appropriately used in the dental office and proved to be quite feasible and promising to be used by the DS in the approach and treatment of patients for smoking cessation.

\section{REFERENCES}

1. Agnihotri R, Gaur S. Implications of tobacco smoking on the oral health of older adults. Geriatr gerontol int. 2009; 14:526-40. http://doi.org/10.1111/ ggi.12285

2. Reibel J. Tobacco and Oral Diseases: Update on the Evidence, with Recommendations. Med Princ Pract. 2003;12(suppl 1):22-32. http://doi org/10.1159/000069845

3. Albert D, Ward A. Tobacco cessation in the dental office. Dent clin North Am. 2012;56:747-70. http://dx.doi.org/10.1016/j.cden.2012.07.004

4. Chaffee BW, Couch ET, Ryder MI. The tobacco-using periodontal patient: role of the dental practitioner in tobacco cessation and periodontal disease management. Periodontol. 2000. 2016;71:52-64. http://doi. org/10.1111/prd.12120

5. Warnakulasuriya S. Global epidemiology of oral and oropharyngeal cancer. Oral oncol. 2009;45:309-16. http://dx.doi.org/10.1016/j. oraloncology.2008.06.002

6. Fiore MC, Jaen CR, Baker T, Bailey WC, Benowitz N L, Curry SEEA et al. Treating tobacco use and dependence: 2008 update. Rockville, MD: US Department of Health and Human Services, 2008

7. Stead LF, Koilpillai P, Fanshawe TR, Lancaster T. Combined pharmacotherapy and behavioural interventions for smoking cessation. Cochrane database syst. rev. [online]. 2016;3. http://doi.org/10.1002/14651858.CD008286.pub3

8. Gordon JS, Lichtenstein E, Severson HH, Andrews JA. Tobacco cessation in dental settings: research findings and future directions. Drug alcohol rev. 2006; 25:27-37

9. Petersen PE. The World Oral Health Report 2003: continuous improvement of oral health in the 21 st century-the approach of the WHO Global Ora Health Programme. Community dent. oral epidemiol. 2003;31(suppl 1): 3-24. http://doi.org/10.1046/j..2003.com122.x 
10. Rosseel JP, Jacobs JE, Hilberink SR, Maassen IM, Allard RHB, Plasschaert AJM et al. What determines the provision of smoking cessation advice and counselling by dental care teams? Br. dent. j. 2009;206:E13-E13. http:// doi.org/10.1038/sj.bdj.2009.272

11. Patel AM, Blanchard SB, Christen AG, Bandy RW, Romito LM. A survey of United States periodontists' knowledge, attitudes, and behaviours related to tobacco-cessation interventions. J. periodontol. 2011;82: 367-76. http://doi.org/10.1902/jop.2010.100405

12. Needleman IG, Binnie VI, Ainamo A, Carr AB, Fundak A, Koeber A et al Improving the effectiveness of tobacco use cessation (TUC). Int. dent. j. 2010; 60:50-9. http://doi.org/10.1922/IDJ_2534Needleman10

13. Davis JM, Ramseier CA, Mattheos N, Schoonheim-Klein M, Compton S Al-Hazmi $\mathrm{N}$ et al. Education of tobacco use prevention and cessation for dental professionals - a paradigm shift. Int. dent. j. 2010;60:60-72. http:// doi.org/10.1922/IDJ 2535Davis13

14. McEwen A. Standard Treatment Program: A guide to behavioural support for smoking cessation. $2^{\text {nd }}$ ed. UK: Department of Health, National Centre for Smoking Cessation and Training; 2014.

15. West R, McEwen A, Lorencato F, Michie S, Churchill S, Willis N. NCSCT Training Standards: Learning outcomes for training stop smoking specialists. 2nd ed. UK: Department of Health, National Centre for Smoking Cessation and Training; 2013.

16. Aveyard P, Begh R, Parsons A, West R. Brief opportunistic smoking cessation interventions: a systematic review and meta-analysis to compare advice to quit and offer of assistance. Addiction. 2012;107: 1066-73. http://doi.org/10.1111/j.1360-0443.2011.03770.x

17. Brothwell DJ. Should the use of smoking cessation products be promoted by dental offices? An evidence-based report. J. Can. Dent. Assoc. 2001:67:149-52
18. Lindson-Hawley N, Hartmann-Boyce J, Fanshawe TR, Begh R, Farley A, Lancaster T. Gradual Versus Abrupt Smoking Cessation. A Randomized Controlled Noninferiority Trial. Ann Intern Med. 2016;164:585-92. http:// doi.org/10.7326/M14-2805

19. Binnie VI. Addressing the topic of smoking cessation in a dental setting. Periodontol. 2000. 2008;48:170-8. http://doi.org/10.1111/j.16000757.2008.00257.x

20. Stead LF, Perera R, Bullen C, Mant D, Hartmann-Boyce J, Cahill K, Lancaster T. Nicotine replacement therapy for smoking cessation. Cochrane database syst. rev. [online]. 2012;11. http://doi.org/10.1002/14651858. CD000146.pub4

21. Shiffman S, West R, Gilbert DG. Recommendation for the assessment of tobacco craving and withdrawal in smoking cessation trials. Nicotine Tob Res. 2004;6:599-614. http://doi.org/10.1080/14622200410001734067

22. Warnakulasuriya S, Dietrich T, Bornstein MM, Peidró EC, Preshaw PM Walter $\mathrm{C}$ et al. Oral health risks of tobacco use and effects of cessation. Int dent. j. 2010;60:7-30. http://doi.org/10.1922/IDJ 2532Warnakulasuriya24

23. Watt RG, Daly B, Kay EJ. Prevention. Part 1: smoking cessation advice within the general dental practice. Br. dent. j. 2003;194:665-8. http://doi. org/10.1038/sj.bdj.4810266

24. Chandwani BP, Perry B, Scrivani S, Kulich RK. Smoking cessation in the dental setting: a practical approach. Gen. dent. 2010;58:318-23.

25. Hanioka T, Ojima M, Tanaka H, Naito M, Hamajima N, Matsuse R Intensive smoking-cessation intervention in the dental setting. J. dent. res. 2010;89:66-70. https://doi.org/10.1177/0022034509350867 